\title{
Retratos literarios del espacio urbano del siglo XX: Barcelona en Pierre Mac Orlan y Michel Deón
}

\author{
LAURA EUGENIA TUdORAS \\ UNED \\ ltudoras@flog.uned.es
}

\begin{abstract}
Resumen: El presente artículo propone un recorrido interpretativo de las imágenes y representaciones literarias del espacio urbano de la ciudad de Barcelona en la primera mitad del siglo XX, plasmadas en dos obras de la literatura francesa, Rues Secrètes de Pierre Mac Orlan y Je me suis beaucoup promené... de Michel Déon.

$\mathrm{El}$ análisis propuesto enfoca dos configuraciones literarias complementarias del Barrio Chino barcelonés, como representación del prototipo de barrio reservado, una coordenada urbana de la gran ciudad, perfilada desde una perspectiva socio-humana.
\end{abstract}

Palabras-clave: literatura francesa, siglo XX, espacio urbano, Pierre Mac Orlan, Michel Déon.

Résumé: Le présent article propose un parcours interprétatif des images et des représentations littéraires de l'espace urbain de la ville de Barcelone dans la première moitié du XXème siècle, recrées dans deux œuvres de la littérature française, Rues Secrètes de Pierre Mac Orlan et Je me suis beaucoup promené... de Michel Déon.

L'analyse qu'on propose envisage deux configurations littéraires complémentaires du Quartier Chinois barcelonais, en tant que représentation du prototype de quartier réservé, une coordonnée urbaine de la grande ville, vue d'une perspective socio-humaine.

Mots-clé: littérature française, XXème siècle, espace urbain, Pierre Mac Orlan, Michel Déon.

Pierre Mac Orlan, considerado en su Francia natal uno de los escritores más importantes del siglo XX, autor de una extensa obra caracterizada por una destacable homogeneidad a pesar de la diversidad de formas que adopta y de la variedad temática que aborda, aunque apenas conocido fuera de su país, encarna, junto a otros grandes escritores franceses, como Michel Déon o Paul Morand, 
por ejemplo, la figura del escritor viajero en el panorama de la literatura francesa del siglo XX.

En el período prebélico, antes de la impactante experiencia de la Primera Guerra Mundial, Pierre Mac Orlan se dedica casi exclusivamente, dada su marcada naturaleza bohemia, a la poesía, a la pintura y a la experiencia del viaje y, a partir de los años 20, ve la luz su mejor obra narrativa, centrada en torno a unos cuantos conceptos-clave que abordan, con originalidad y con un alto grado de expresividad poética, la vida contemporánea, en una recreación literaria del pintoresco social, retratado desde una mirada que impregna nobleza y humor a las imágenes recreadas.

Su obra invita a un descubrimiento poético del mundo, a través de la variedad de imágenes con las que el recorrido literario aúna reflejos de las grandes ciudades del mundo.

Nuestra atención se centra especialmente en Rues Secrètes (1934), un viaje literario que nos adentra en un paisaje social de mediados de los años 30, configurado por los barrios reservados de grandes ciudades como Túnez, Casablanca, Berlín, Estrasburgo o Barcelona. Es esta última referencia urbana la que será objeto del presente estudio.

Por otra parte, la producción literaria de Michel Déon, miembro de la Academia Francesa, es considerada un testimonio y un reflejo de la Europa del último medio siglo, y reúne, en un considerable número de obras, imágenes que recrean diversos lugares del mundo, pinceladas entre impresiones y ficción literaria.

En 1995, el escritor agrupa bajo el título Je me suis beaucoup promené... una serie de relatos de viaje, algunos publicados anteriormente en revistas ya desaparecidas, otros escritos mucho tiempo antes pero no publicados, y algunos otros de creación más cercana a la fecha de aparición del volumen, que presentan globalmente el aire de un recorrido iniciático a través de distintos rincones europeos a finales de los años 40 y principios de los 50 .

Junto a imágenes de Grecia, Italia, Irlanda o Francia, encontramos una estampa española en la que el reflejo central recrea la ciudad de Barcelona, ciudad que ocupa nuestra atención en el marco de las ciudades presentadas.

A través de las representaciones literarias de este espacio común a Rues Secrètes y Je me suis beaucoup promené... que es Barcelona, nos proponemos rescatar la imagen de la ciudad de la primera mitad del siglo, contraponiendo las distintas configuraciones narrativas plasmadas en estas dos obras.

Barcelona, cuyo nombre está marcadamente vinculado a un notable y reconocido prestigio cultural, ha sido durante mucho tiempo, no sólo la capital de la literatura catalana, sino una ciudad de gran interés para los escritores de lengua castellana, así como para muchos escritores extranjeros. Durante gran parte del siglo XX, la ciudad ha representado el papel de capital cultural de España, consiguiendo proyectar una imagen muy favorable en el exterior, como centro de atracción intelectual, cultural y artístico. 
En el marco de esta imagen que ha ido concentrando con el tiempo un importante bagaje simbólico, el punto más atractivo de la geografía barcelonesa para los escritores y los artistas en general, es el distrito V, llamado también Barrio Chino, que recibe en los años setenta el nombre de Raval, recuperando así su nombre medieval, procedente del término árabe rawal, que se traduce como 'fuera de las murallas'. El Raval es un barrio céntrico de la ciudad, cuyo desarrollo urbanístico se produjo en la primera mitad del siglo XIX, barrio en el que se instalaron las primeras industrias de la época, lo que provocó, en lógica consecuencia, la llegada de la clase obrera. Las primeras dos denominaciones, Barrio Chino y Distrito V, son términos relacionados con la marginalidad y, en general, con la prostitución.

Este barrio ha sido considerado, dada su reiterada presencia en la literatura, el rincón más literario de la ciudad, encontrándose múltiples referencias, descripciones y representaciones de este conjunto de calles barcelonés. Como señala J. Rius Uldemollins, «el Raval ha ejercido un notable poder de atracción hacia los escritores extranjeros» (Rius Uldemollins 2008: 188).

Recuperando con la ayuda de materiales propios de la geografía urbana, la imagen real de la ciudad de los años en los que proyectan Pierre Mac Orlan y Michel Déon sus relatos, encontramos, en el Barrio Chino, un decorado hecho de callejuelas estrechas, abarrotadas de gente en la entrada de los bares, viviendas que sirven de comercios y talleres a la vez que de casas, negocios que giran en torno a la prostitución, una prostitución que marca visible y cotidianamente el barrio.

Robert Ferras, especialista en geografía urbana, perfila en su tesis doctoral, publicada en el año 1977, Barcelone, croissance d'une métropole, un retrato objetivo del Barrio Chino de aquellos años, en un capítulo acertadamente titulado Les taudis sont aussi dans «le centre»:

Le Vème district est entré dans le folklore barcelonais sous le nom de «quartier chinois», auréolé d'une concentration rare de bars à matelots comme le veut la légende. Il s'encombre d'idées reçues découlant de son investissement par la prostitution et les petits métiers qui gravitent autour d'elle. On y rencontre des touristes en mal d'exotisme à bon compte, c'est le Hong-Kong à la portée de l'Européen moyen.

Un des secteurs les plus dégradés de cette sorte de médina, bien délimitée par les Ramblas et les Rondas, se caractérise par la vétusté des logements; près de $90 \%$ datent au moins du siècle dernier, $12 \%$ ont été bâtis entre 1900 et la Grande Guerre; aucun n'est postérieur à 1918 (à l'exclusion de l'ébauche de l'Avenue García Morato)...

Dans un décor de rues étroites et achalandées c'est le monde des hommes seuls formant des groupes animés devant l'entrée des bars, les plus fortunés se trouvant à l'intérieur. Au-dessus, des chambres sordides; ça et là les vitrines éclairées des pharmacies spécialisées dans le traitement des maladies vénériennes. Patios et rues n'atteignent pas le tiers de l'ensemble; et la pénurie en surfaces libres est d'autant plus pesante que les maisons atteignent cinq étages en moyenne, réduisant d'autant l'ensoleillement des venelles. 
Les locaux professionnels contribuent à l'encombrement du quartier et accroissent la pollution sonore.

Le type d'occupation mixte est très répandu, le logement se mêlant aux commerces, aux bureaux, aux ateliers; cela réduit d'autant la superficie habitable et le nombre de pièces par logement...

C'est la prostitution qui marque le plus le quartier au niveau des bars, des loueurs de chambres; s'y ajoutent les pseudo-salons de coiffure, les pharmacies et les boutiques d'articles d'hygiène ouvertes toute la nuit. (Ferras 1977: 230231).

Con esta perspectiva sociológico-urbana del Barrio Chino barcelonés, legendario durante décadas, accedemos a un mismo espacio a través del capítulo dedicado a la ciudad en Rues Secrètes, titulado Le Quartier Chinois de Barcelone, por Pierre Mac Orlan, cuya emotiva escritura refleja una mirada que se acerca paulatinamente a los rincones más inesperados y secretos del barrio, con la delicadeza propia de quien es capaz de detectar la presencia de la belleza en los lugares más inhóspitos.

En esta dimensión narrativa, casi novelesca, se produce desde un principio un desdoblamiento de lo urbano que contrapone la ciudad honesta y la ciudad de la aventura, sin que esta última se vea especialmente recargada de connotaciones negativas.

El discurso literario que recrea la realidad y la problemática social del Barrio Chino en los años 30, se viste de un impactante calor humano que refuerza la fantasía y la calidez del ambiente recreado, revistiendo de tintes de aventura esta compleja y dura realidad:

Il suffit d'un tout petit noyau de vie clandestine mais puissante pour apporter dans une cité honnête la présence de l'aventure, cette aventure difficile à définir et qui n'est, presque toujours, qu'une image de rébellion pittoresque. Comme Amsterdam, Hambourg, Marseille et Paris, Barcelone est une ville d'aventures. Tout cela se passe, bien entendu, en dehors de l'imagination de sa population laborieuse, calme et gaie. (Mac Orlan 2009: 81).

Esta misteriosa ciudad paralela, encarnada por el Barrio Chino, se configura como un espacio plagado de elementos pintorescos, más propios de la imaginación que de la realidad urbana, ofreciendo una estampa que parece extraída de la literatura decimonónica:

Il faut se mêler à la population pittoresque qui peuple des rues prédestinées, qui sont comme l'arrière-boutique des magasins où l'on vend des aventures à façon et des crimes taillés sur mesure. (Mac Orlan 2009: 82).

Mac Orlan excluye a priori la ciudad de las coordenadas españolas reconocibles, de los aspectos puramente identitarios, reflejándose así Barcelona como una gran ciudad moderna, equiparable a cualquier otra gran ciudad europea: 
La nuit de Barcelone au printemps est parfumée comme une chanson d'amour. Le caractère espagnol et maure n'intervient pas. C'est une grande ville moderne, dont les traditions ne sont pas très apparentes. (Mac Orlan 2009: 82).

Se desprende de esta plasmación literaria, una imagen cálida, extremadamente humanizada y viva de la ciudad que, a nivel global, es evocada por la memoria de los recuerdos pasados, recargados de actualidad, de inmediatez, de una sensación gentilmente familiar. La recuperación textual del espacio urbano remite someramente a puntos de referencia identificables, como la rambla de San José, la iglesia de Belén u otros, pero la auténtica ciudad de Mac Orlan se recrea en una extremadamente sutil y expresiva evocación de sentimientos y sensaciones, de percepciones únicas, de detalles inesperados que logran una equivalencia innegable entre el espacio urbano y el espacio humano. En esta dimensión intensamente sensitiva a la par que humana, Barcelona despliega en una de sus imágenes más representadas, la de las Ramblas, una urbanidad elegante, cortés, que le deja al viajero la posibilidad de completar, con la fantasía, las representaciones urbanas que lleva después consigo:

C'est sur les ramblas que l'on peut se rendre compte de l'urbanité courtoise de cette charmante ville catalane dont on garde un souvenir amoureux. (Mac Orlan 2009: 82).

Desde esta visión global sobre la ciudad, el texto invita a recorrer a través de representaciones literarias diversas, su barrio más famoso, el Barrio Chino, cuya anterior presencia en la literatura, en numerosas descripciones, inducía, según el autor, a una representación imaginaria que abarcaba una amplitud netamente superior a la real y cuyo halo, revestido de confabuladora fantasía, plasmaba una imagen más cercana a una nueva ciudad que englobaba también Barcelona:

...on peut croire que Barcelone est une ville tout entière englobée dans son fameux quartier chinois. C'est très loin d'être exact. La première fois que je pénétrai dans le Barrio Chino, je fus stupéfait de son peu d'importance: quelques rues... (Mac Orlan 2009: 83).

Recuperamos, de este modo, una de las configuraciones literarias más entrañables de la época, el Barrio Chino convertido en una pequeña ciudad casi secreta, paradójicamente conocida en el mundo, no sólo mediante el conocimiento directo de los viajeros y de las experiencias allí acaecidas, sino también gracias a las múltiples recreaciones literarias que confieren al barrio el estatus de una gran ciudad destinada al placer, un escenario socio-humano en el que el escritor encuentra una inagotable fuente de inspiración para sus posibles personajes:

J'avais lu des descriptions parfaitement évocatrices de ce quartier célèbre et je m'étais imaginé une gigantesque ville du plaisir, tantôt mal éclairée, tantôt lumineuse à l'excès. Je savais, en entrant dans ces rues, que je trouverais tel établissement à droite, telle maison close à gauche. Les choses décrites s'y trou- 
vaient bien, mais considérablement plus petites que je les avais imaginées. (Mac Orlan 2009: 83-84).

Las vivencias experimentadas en la pequeña y secreta ciudad de las aventuras, perfilan una atmósfera compuesta de fervor, alegría y diversión, de espectáculo desenfrenado y de emociones desbocadas, contrarrestadas por la perceptible presencia de una pobreza acentuada, de una sordidez tolerada. Sin embargo, el relato refuerza el lado humano de las estampas presentadas, consiguiendo impregnar, una vez más, cierto grado de ternura y aceptación de una realidad social excluida de lo comúnmente aceptable y aceptado.

Las figuras femeninas de esta peculiar dimensión urbana reúnen un doble perfil que combina en la misma medida, miseria y nobleza:

Ces jeunes femmes étaient jolies, et elles provoquaient les spectateurs par leurs danses sans aucune vergogne... elles affirmaient leur misère avec une sorte d'orgueil sensuel et pardonnable. (Mac Orlan 2009: 91).

Las calles secretas del barrio alternan las manifestaciones de la dualidad propia del mundo de la actuación, en la dimensión de la fantasía nocturna, llena de colores, luces y embriaguez sensorial y en la dimensión correspondiente a las circunstancias sociales y humanas posteriores, despojada de detalles artífices que, aparentemente, transforman fugazmente en fantasía la más descarnada y evidente realidad:

Le spectacle de l'après-midi me parut tout de suite extraordinaire... au Barrio Chino il semble bien que la faim, au milieu de tous ces haillons de couleur et de ce luxe indigent, règne en maîtresse. Quand la danseuse s'arrête, qu'elle disparaît de la scène, c'est comme une lumière qui s'éteint brusquement. La même femme, dans sa loge qui surplombe la salle, vêtue sans coquetterie, apparaît terne et dolente ainsi qu'une pauvresse. (Mac Orlan 2009: 91-92).

La galería de personajes que reconstruye el relato de Mac Orlan, ofrece un retrato preciso y sensible del pintoresco crisol social que confluye en las calles del Raval, siempre esbozado desde la más tierna perspectiva narrativa, con una ternura que troca lo sórdido en honorable, lo infame en delicado, siempre destilándose, en la escritura, la tácita y constante simpatía del autor.

Rues Secrètes propone, en suma, una visión urbana repleta de mínimos detalles que sobrepasan las apariencias, que rozan y participan inesperadamente de la belleza, en el corazón del barrio más reservado de Barcelona:

S'il est un endroit au monde où la puissance de la vue signifie le bel épanouissement des femmes et des fleurs, c'est bien à Barcelone qu'il faut le situer... L'amour pousse ici comme les fleurs veloutées et robustes. (Mac Orlan 2009: 100-101).

Complementario al reflejo literario propuesto por Mac Orlan, el que nos ofrece Michel Déon en Les clés du «Barrio Chino», relato integrado en Je me 
suis beaucoup promené..., enmarca la imagen de Barcelona en una perspectiva global de la España de la década de los años 40:

À la fin des années 40, au début des années 50, Barcelona était la dernière étape obligée d'un voyage en Espagne. On y accédait par des routes impossibles depuis Madrid ou Alicante, ayant crevé dix fois, cassé les quatre amortisseurs, la carrosserie menant un bruit d'enfer dans un panache de poussière. Les gardes civils... se raclaient la gorge et salivaient pour humecter leurs bouches desséchées et répondre que oui, on était bien sur la route de Barcelone, que c'était seulement un mauvais tronçon et que, cent kilomètres plus loin, on trouverait de l'asphalte, des arbres pour l'ombre, des fontaines publiques pour y plonger la tête. En un mot, on serait en Catalogne. On les laissait derrière soi dans l'hostile désert aragonais..., rêvant peut-être à ce que l'étranger, le fou qui roulait à l'heure de la sieste, trouverait comme récompense à son entrée à Barcelone. À la lueur qui s'était allumée une seconde à peine dans leurs yeux..., on savait déjà que Barcelone était un mythe pour ces Castillans secs comme des allume-feu, dévorés de soif... (Déon 1995: 149-150).

Real e imaginario, impresiones de viaje y leyenda se combinan y construyen una identidad urbana, a través del discurso literario que engloba una percepción a la vez sensible y material de la ciudad, que refuerza el poder sugestivo del mito:

Et c'est vrai qu'après ces centaines de kilomètres, l'entrée dans Barcelone était comme un ballon d'air frais, de senteurs marines. La ville en soi n'offrait rien de particulièrement attrayant malgré les folies de Gaudi et le gothique attardé de Josep Puig. À y regarder de près, elle était même plutôt grise et poussiéreuse, surpeuplée, sans la majesté de Madrid, affairée, sans la merveilleuse nonchalance de Séville, mais plus on y pénétrait, plus la cité s'ouvrait comme une figue de Barbarie: les défenses tombaient, l'intérieur se révélait suave et doux. (Déon 1995: 150).

La imagen general de la Barcelona de mediados del siglo XX da cuenta de un acercamiento sensible, mezcla de sensación y afectividad, que introduce poco a poco en su ambiente socio-urbano y, al mismo tiempo, refleja plenamente la mirada exterior del viajero extranjero, procedente de coordenadas culturales diferentes:

Je parle d'une époque où les visiteurs étaient rares et se faisaient rappeler à l'ordre s'ils ôtaient leurs vestes dans un café, où personne n'aurait osé circuler en short dans les rues,... où, enfin, il fallait un visa pour entrer en Espagne... La Généralité de Catalogne pansait ses blessures plus vite que le reste de l'Espagne... (Déon 1995: 150).

Con la naturalidad propia del discurrir del lenguaje que ordena las impresiones o las ficciones imaginando el mundo, el relato del periplo barcelonés añade una representación comparada de los habitantes de la ciudad, especialmente de las mujeres catalanas, distinguiendo concisamente entre la cultura catalana y la cultura española en general. 
De este modo, el perfil de la barcelonesa recupera la imagen de una mujer distinta a la de las demás regiones del país, una mujer cuya actitud y comportamiento resultan, a los ojos del extranjero, más refinados y más propios de un mundo culturalmente más cercano al suyo:

Dans la rue, les femmes ne provoquaient pas comme les Madrilènes ou les Sévillanes...Elles n'en étaient pas moins belles dans leurs sévères robes noires ou grises... comme les a immortalisées Maillol le Catalan... On aimait le cerne de leurs grands yeux de femmes qui sortent d'une sieste amoureuse. Elles maniaient moins agressivement l'éventail et parlaient d'une voix plus basse. Nous n'étions plus vraiment en Espagne et pourtant nous y revenions à la tombée de la nuit. (Déon 1995: 150-151).

El panorama urbano nocturno conduce hacia la vieja Barcelona, hacia el Barrio Chino que se vislumbra como una isla oscura en la alfombra de luces contemplada desde el Tibidabo. El relato recupera, desde un principio, la fama del barrio, a través de una escena en la que las tripulaciones de los barcos atracados en el puerto se lanzan al asalto de los conocidos bares de las llamadas mujeres de mala nota.

El Barrio Chino se configura en esta visión literaria, como un espacio de convergencia y de interrelación de múltiples y variadas culturas, un espacio marcado por un cambio continuo, en el que interfieren siempre nuevos actores, personajes nuevos de intervenciones fulgurantes, relaciones superfluas.

Traspasa, sin embargo, visiblemente, a través del recuerdo entrelazado con la construcción imaginaria de la ficción, el marcado carácter multicultural que emana el barrio, perceptible desde un primer contacto. La ciudad muestra, a través del espejo polifacético que es el Barrio Chino, su rostro más abierto al elemento externo, y la diversidad que define su urbanidad reúne nacionalidades, idiomas, culturas, costumbres, que conjuntamente perfilan el mito del que la literatura se nutre y, a su vez, mantiene viva la leyenda, leyenda que, en aquellos años, atravesaba las fronteras y atraía, tanto a extranjeros como a jóvenes burgueses barceloneses, hacia el encanto de la decadencia allí instalada y que, a principios de los 50, reunía todos los componentes característicos de los bajos fondos urbanos.

Más allá de la elaboración de imágenes perdurables o de reputaciones, el relato de Michel Déon recrea, como testimonio literario y como recurso cognitivo, en cierto modo, la configuración socio-urbana del barrio, correspondiente a aquellos años, plasmando en la narración signos y paisajes identificadores reconocibles.

Al mismo tiempo, en una presentación inicial de conjunto, que pasa revista a los componentes del cuadro presentado, se entremezclan detalles chocantes de una realidad geográfica y sociológica comprobada con detalles configuradores de una visión urbana imaginada, que refuerza este segmento urbano en su dualidad, asentada sobre lo sórdido y lo grandioso, sobre una realidad fuera de las normas aceptadas y sobre una libertad bohemia no encontrada en otras partes: 
Le «Barrio Chino», qu'est-il devenu? Je ne l'ai pas revu depuis plus de trente ans et je n'y retournerai probablement jamais, conservant le souvenir de la folie secrète qu'il engendrait après la guerre quand tout le monde, pêle-mêle, s'y retrouvait dans les vapeurs de l'alcool. C'était un quartier entièrement inventé par un Fellini catalan, à la fois grandiose et sordide: un dédale imprévisible de ruelles malodorantes... Le nombre des monstres qu'on y côtoyait semblait infini: femmes obèses sanglées dans des robes de poupées, unijambistes, manchots, borgnes, aveugles et surtout des nains. Il semble que tous les nains d'Espagne se donnaient rendez-vous au Barrio Chino. (Déon 1995: 151-152).

El discurso literario, creador de espacios urbanos, remite constantemente a la presencia de las mujeres en las calles, en diversos locales, en el bullicio de la vida nocturna, reuniendo un conjunto de representaciones que crean una sensación de permanencia que las fija como elementos casi estructurales de lo interior y de lo exterior, como partes ineludibles de la vertebración urbana:

«Ce soir, nous allons chez Lopez!... c'est pour Manita, une petite Courdouane, un bijou, une perle blanche. Rends-toi compte qu'à seize ans elle n'a jamais vu la lumière du jour, elle ne vit que la nuit. Un vrai sorbet au citron. On n'éduque plus les filles comme ça aujourd'hui,... Où va le monde?...» (Déon 1995: 153);

Cela voulait dire qu'aux dernières nouvelles une bodega venait de s'ouvrir avec les Andalous les plus sauvages du monde et des filles admirables; bandantes à en mourir... (Déon 1995: 155).

El auténtico acceso al corazón del Barrio Chino se produce de la mano del enano Bavastro, que les introduce y les guía por el caudaloso flujo de vida que despliegan los trasfondos más escondidos e inaccesibles del barrio. La descripción realizada por el autor, remite involuntariamente a la imagen de los burdeles parisinos de Montmartre, así como el personaje de Bavastro nos recuerda, de algún modo, a Toulouse-Lautrec:

Ce qui faisait pardonner à Bavastro son absence de scrupules et sa voracité, c'était sa connaissance prodigieuse de tout ce qui se tramait au Barrio, en particulier l'arrivée de nouvelles filles...

Grâce à Bavastro, on ne perdait pas de temps à tâtonner pour découvrir la fine fleur du Barrio, on le suivait partout dans des tascas infâmes tapies au sous-sol, dans des greniers étouffants où il y avait bien trente hommes à manger des yeux une fille qui leur dévoilait à peine une épaule, une cuisse en un éclair. (Déon 1995:153).

Se trata de un acceso lleno de magia, magia asociada no sólo al conocimiento profundo de los rincones más sórdidos y recónditos del barrio, sino también a la magnífica imaginación del enano, que jalona el recorrido con increíbles historias absolutamente delirantes, en un despliegue fantástico de sensaciones que transfiguran el rostro del distrito, convirtiéndolo en un espacio mágico, a la par que atractivo, donde realidad y ficción pueden llegar a confundirse: 
...l'imagination suppléait à ses trous de mémoire, et rapidement il expliqua à nos interlocuteurs d'un soir que nous avions, lui et moi, convaincu Staline d'entrer en guerre aux côtés des Alliés, fait pleurer le Pape en lui racontant notre évasion de Buchenwald et servi le même canon dans un régiment de la Légion. Sa main atrophiée? Un obus avait coupé le bras, et Bavastro, sans perdre la tête pour autant, avait ramassé des morceaux de sa main atrocement mutilée pour que le chirurgien puisse la coller au moignon restant. Je cite cela entre autres blagues monumentales, défiant toute réalité et que, la nuit avançant et l'alcool aidant, un auditoire toujours béat gobait sans protester. (Déon 1995: 154155).

Volviendo, unos años más tarde, descubren que el rastro del enano se ha perdido y que nadie en el barrio sabe nada de él, quedando inevitablemente ligada la imagen de esa Barcelona fantástica con la pequeña figura del misterioso enano:

Il s'était volatilisé, me laissant les clés du Barrio, ce dont je fis profiter encore quelques amis avant de décider que je n'y retournerais plus, qu'une certaine magie s'était dissipée, que, pour d'autres, le talent qui se dépensait dans les tascas et les bodegas exercerait la même fascination, mais que pour moi l'intercesseur mystérieux, le nain au bras atrophié ne serait plus là pour que rebondisse la fête. (Déon 1995:156-157).

El viajero deposita simbólicamente las llaves del Barrio Chino y nos las hace llegar a través de su escritura, aunque nunca más podamos acceder a la Barcelona de los años cincuenta, más que a través de la magia de la lectura.

\section{BIBLIOGRAFÍA}

DÉOn, M. (1995), Je me suis beaucoup promené..., Paris, La Table Ronde.

FERRAS, R. (1977), Barcelone, croissance d'une métropole, Paris, Éditions Anthropos. Mac Orlan, P. (2009), Rues Secrètes, Paris, Arléa.

Rius Uldemollins, J. (2008), Los barrios artísticos como base local de la cultura global. El caso del Raval de Barcelona, en: Revista Internacional de Sociología (RIS), vol. LXVI, n. ${ }^{\circ}$ 51, Madrid, CSIC. 